Article

\title{
The Interplay between Job Control, SOC Strategies, and Age in Sustaining Work Ability in a Sample of Administrative Employees
}

\author{
Ilaria Sottimano, Gloria Guidetti *, Sara Viotti ${ }^{\circledR}$ and Daniela Converso \\ Department of Psychology, University of Turin, via Verdi 10, 10124 Turin, Italy; ilaria.sottimano@unito.it (I.S.); \\ sara.viotti@unito.it (S.V.); daniela.converso@unito.it (D.C.) \\ * Correspondence: gloria.guidetti@unito.it
}

Received: 5 February 2019; Accepted: 1 March 2019; Published: 9 March 2019

check for updates

\begin{abstract}
In recent years, the average age of workers has risen. Because of that, work ability is reducing in many sectors, especially in a public context. Given the above, it is necessary to investigate the individual and organisational resources that can play a role in the protection of work ability. This study investigates the work ability of administrative workers, examines selection, optimisation, and compensation (SOC) as a form of mediation between job control and work ability, and explores the relationship of job control, age, work ability, and SOC strategies via moderated mediation models. The findings indicate that job control, SOC strategies, and age correlate to work ability, but the effect of these factors is different. Job control and SOC strategies are positively related to work ability, and job control positively relates to the use of optimisation and compensation. However, only optimisation and compensation strategies mediate the association between job control and work ability. Finally, age moderates the effect of job control on work ability. The findings suggest that interventions, such as SOC training, promotion, and job control, may help to sustain work ability among elderly administrative workers.
\end{abstract}

Keywords: selection; optimisation and compensation; work ability; age; administrative sector

\section{Introduction}

In the last decades, the world of work and organisations has changed. Technological evolution has led to the increasing use of computers in several work environments [1], and, in some cases, it has reduced the need for the job itself. Meanwhile, an ageing population persuaded decision-makers to raise the usual retirement age, leading to a significant increase in older workers. In this context, the European Foundation for the Improvement of Living and Working Conditions [2] affirmed that "sustainable work means achieving living and working conditions that support people in engaging and remaining in work throughout an extended working life". A change in workers' conditions during their lifespan should then be compensated through several interventions, such as transformations in the workplace (i.e., ergonomic adaptations) or job redesign. Moreover, organisations should foster workers' physical and mental health over their lifespan, despite the loss of resources. Work ability, a descriptor of the physical and intellectual resources on which individuals can rely to respond to the emotional, cognitive, and physical demands posed by their work [3,4], can represent a significant indicator to monitor the sustainability of work during the extended working life.

\section{Work Ability and Ageing}

Several studies indicated that age is significantly and negatively associated with work ability [5-10]. Ilmarinen and Ilmarinen [11] explained that this decline is due to the imbalance between 
individual resources and the demands of the job, namely the work and the organisational context not being aligned to the age-related changes in personal resources.

Reflecting on this topic is important because workers with decreased work ability are at greater risk of reduced productivity at work, and poor work ability is predictive of sickness absences, early retirement, disability pensions, intention to leave, stress, and depression [3,5,8,12-14].

This theme has assumed a strong relevance in recent years, given the increase in the average age of workers: in Europe, the employment rate in the 55-64 years old cohort increased by $9.8 \%$ in 2008-2016, and the percentage of workers aged over 55 in Italy was 46.2\% in 2014 [15]. Workforce ageing is more pronounced in the public service than in the private sector, especially in Italy, where the percentage of employees aged 50 years or older in the public sector was more than $50 \%$, while the same percentage in the total labour force was around $40 \%$ [16]. In the Italian public administration (PA), in 2001, the average age was 44.2 years, while in 2016, it was 50.7 years. Distribution by age groups makes the Italian demographic picture in the PA even more alarming: in 2016, only $2.7 \%$ of the public workers were $18-29$ years old; $11.5 \%$ were $30-39$ years old; $29.5 \%$ were $40-49$ years old; $41.3 \%$ were $50-59$ years old; and 15\% were over 60 years old [17]. Consequently, problems related to ageing and the critical issues associated with this phenomenon are particularly significant in the public sector.

\subsection{Job Control and Work Ability}

One of the questions with regard to an ageing workforce is how employees can maintain their function with an acceptable level of work ability over their lifespan, despite a loss of resources. The job demands-resources model (JD-R) [18] assumes that work factors which affect workers' psychological health can be classified into two categories: job demands and job resources. Job demands (those aspects of the job that require workers to sustain psychological or physical effort) are associated with costs in terms of health, and job resources (those physical, psychological, social, or organisational aspects of the job that may help to achieve work goals, reduce job demands and the related physiological and psychological costs, and stimulate personal growth and development) lead to a positive effect on organisational outcomes. Regarding this model, several studies showed that work ability could be sustained by some resources, such as job control. Job control describes autonomy in making job-related decisions and the opportunity to use skills at work. In the job demand-control-support (JDC-S) model [19], Karasek (1979) underlines the importance of control to sustain well-being at work. According to this evidence, studies showed that job control can attenuate the negative impact of age on work ability [10]. Similarly, Van den Berg et al. [8,9] observed that the negative effects on work performance of decreased work ability could be partly counterbalanced by increased job control, while McGonagle et al. [20] observed that skill discretion moderated the negative relationship between job demands and work ability. More generally, the literature highlighted that decision authority [21-25] and skill discretion [23,25-28] were very important dimensions in promoting work ability and well-being at work. The lifespan perspective on work design [23] proposed that some job resources had a stronger positive relationship with indicators of occupational well-being among older workers. More specifically, the literature showed that job control $[21-24,27,28]$ was a very important resource for work ability, and in particular, for older workers.

\subsection{SOC Strategies and Work Ability}

Another model that has been associated with work ability is the Selection, Optimization and Compensation (SOC) model; it proposes that in situations characterised by high demands and limited resources (that may occur during ageing), individuals can make use of a set of four strategies that help them to invest their resources in an optimal way [29-33]. In fact, employees often face multiple demands and pursue several goals simultaneously. However, their resources might not always suffice to meet all demands, and thus, employees need to adapt their behaviour to deal with requests. Freund and Baltes [34] consider SOC strategies as goal-related behaviours. Selection refers to priorities and objectives based on personal preferences (elective selection) or due to perceived loss of resources 
(loss-based selection). A key aspect of elective selection is the choice of a small number of goals. Optimisation involves investment of time and energy into the acquisition of goal-relevant means, while compensation involves the acquisition and application of alternative strategies or use of external aids (e.g., technology) to maintain a desirable level of performance when previous resources have been lost. In sum, people can implement these strategies by selecting the aspects of their lives that are important to them, optimising the resources and tools that help them achieve their goals in the selected areas, and compensating for losses by adapting to vital environmental changes. Some authors argue that the four strategies act in a synchronised and coordinated way [31] and represent "one combined and orchestrated process" [32]. The synchronised use of SOC strategies enables successful ageing [31]. Over the years, researchers have demonstrated that the use of SOC strategies predict outcomes, such as work ability, job performance, and occupational well-being.

A recent study by Weber et al. [29] found that favourable working conditions, in terms of a high degree of job control, as well as individual compensation strategies, could help older employees to maintain work ability. Similarly, Weigl et al. [30] found that the negative relationship between age and work ability was weakest for employees with a high level of job control and significant use of SOC strategies. Moreover, Von Bonsdorff et al. [35] observed that using SOC strategies at work can help employees compensate for resource loss, which results in a better balance between employees' resources and job requirements; that is, their work ability. In 2014, some authors [36] provided evidence for positive associations of job resources with work engagement, mediated through the use of SOC. Baltes et al. [32] observed that SOC strategies could protect against work-family conflict. In this view, SOC strategies can help older workers cope with age-related declines [37,38].

\subsection{Interplay between Job Control, SOC Strategies, and Work Ability}

Some studies considered the relationship between job control, SOC strategies, and work ability. For example, Müller et al. [39] showed that job control and SOC were positively related with work ability, and that the positive effect of job control on work ability was significantly mediated through SOC in a sample of nurses. Similarly, Weigl et al. [30] suggested that the use of SOC strategies and job control were conducive to maintaining the work ability of ageing employees. However, Müller et al. and Weigl et al. affirmed that the use of the four SOC strategies was necessarily "orchestrated", "synchronised", and "coordinated", considering only a little the impact of the four single strategies. Few studies have paid attention to each single component of the SOC model. For example, Zacher et al. [38] found that optimisation and compensation were useful for maintaining work engagement, and Weber et al. [29] observed that only compensation had a positive effect on work ability. As a result, Segura-Camacho et al. [40] recently said that it is necessary to consider the role of the four SOC strategies.

\subsection{Aims of the Study}

The goal of this study is to investigate the work ability of administrative workers and the interplay between job control, selection (elective and loss-based), optimisation, compensation at work, and age in determining work ability in administrative workers.

As previously reported, job control and SOC strategies can positively impact work ability; however, no previous study has tested the mediation role of SOC strategies, considered as four sub-dimensions, between job control and work ability. Consequently, one of the aims of the study is to provide additional and more detailed information on the role of the four sub-dimensions of SOC. Furthermore, in an original way, compared to previous research, our study tested the roles of moderation, either direct or indirect, and of age, imagining that the use of job control and SOC strategies were more relevant with increasing age [33,34,37,38].

These goals were important in order to identify elements of support for work ability and sustainability at work, and to provide useful indications for the planning of organisational interventions [41-44]. 


\subsection{Hypotheses}

We developed the following hypotheses:

Hypothesis 1 (H1). Job control is positively related to work ability.

Hypothesis 2 (H2). The use of SOC strategies at work (all four single strategies) is positively related to work ability.

Hypothesis 3 (H3). Job control is positively related to the use of elective selection, loss-based selection, optimisation, and compensation.

Hypothesis 4 (H4). The use of SOC at work (all four single strategies) mediates the relationship between job control and work ability.

Hypothesis 5 (H5). Age might play a role as a moderator in the direct or indirect effect (including path a: job control-work ability; and path b: SOC strategies-work ability) of job control on work ability. More specifically, age might play the part of a moderator in: (1) the relationship between job control and work ability; (2) the relationship between job control and SOC strategies; and (3) the relationship between SOC strategies and work ability.

According to our hypotheses, we confirm that job control, elective selection, optimisation, and compensation at work are factors that help to protect work ability, especially as workers get older. Moreover, job control also affects work ability indirectly, through optimisation and compensation strategies.

\section{Materials and Methods}

\subsection{Participants}

In December 2017, as part of an agreement between the Municipality of Turin and the Department of Psychology of the University of Turin, a self-report questionnaire, aimed at assessing job well-being among workers, was sent to the institutional e-mail of the administrative employees of the Municipality of Turin, and 1704 people answered it. Thanks to the agreement between the University and the Municipality, it has been possible to access a lot of data on the well-being and work ability of public workers in Turin. The population of municipal workers in Turin is prototypical. Turin is, in fact, the fourth largest city by number of inhabitants and one of the most important economic bases in Italy. Moreover, most of the municipal workers were hired in the 1980s and 1990s, and today they are over 50 years old. More specifically, the Municipality of Turin has 9531 employees, with an average age of 52.9 years. The employees of the Municipality of Turin are older than workers in the Italian public administration, so predict the critical issues that will occur in the wider public context in a few years.

Participation in the survey was voluntary. The research conforms to the provisions of the Declaration of Helsinki in 1995 (and subsequent revisions), and all ethical guidelines were followed as required for conducting human research, including adherence to the legal requirements of the country of study (Italy).

\subsection{Measurements}

The questionnaire was specifically developed for this study. It included the following:

- $\quad$ Outcome variable: The work ability index (WAI) [45] is a widely used tool that measures the perception of sustainability at work derived from the construct of WA. The WAI contains seven items, each of which gives a partial score that contributes to forming the overall WA score (range: 7-49, Cronbach's $\alpha=0.72$ ). The seven items measure the following: (1) current WA compared 
with lifetime best (range: 1-10); (2) WA in relation to mental and physical demands of the job (range: 2-10); (3) number of current diseases diagnosed by a physician (range: 1-7); (4) estimated work impairment due to diseases (range: 1-6); (5) sick leave during the past 12 months (range: 1-5); (6) self-prognosis of WA for the next two years (scores: 1-4 or 7); and (7) mental resources (range: $1-4)$.

- Independent variable: Job control. According to Karasek [19], there are two dimensions of control: skill discretion and decision authority. Job control was measured with the job content questionnaire (JCQ), which contains eight items that investigate the decision latitude (Cronbach's $\alpha=0.76$ ). Five items measured skill discretion (e.g., "People I work with are competent in doing their jobs"), and three items measured decision authority (e.g., "My job allows me to make a lot of decisions on my own"). Responses on subscales were given on a 4-point scale with a range of 1 = strongly disagree to $4=$ strongly agree. Scores ranged from 0 to 24 .

- Mediation and moderation variables: Age and SOC. The SOC questionnaire [46] is a 12-item scale used to assess SOC strategies: selection (S; e.g., "I focus all my energies on a few goals"), optimisation (O; e.g., "If I care about something, I dedicate myself to it completely"); and compensation (C; e.g., "When things do not go as well as usual, I look for other ways to achieve the same results"). On the original SOC scale, each item consists of two alternative statements: one referring to SOC techniques and one referring to non-SOC strategy. Participants were asked to decide which one of the alternatives best fit their behaviour [47]. In the present study, to reduce cognitive complexity and potential item ambiguity, we used a 4-point Likert format $(0=$ strongly disagree to $3=$ strongly agree $)$.

\subsection{Statistical Analysis}

All statistical analyses were conducted by using SPSS 25. Preliminary analyses included descriptive statistics, independent $t$-tests, analysis of variance (ANOVA), and Pearson correlation analyses.

The mediation and moderated mediation models were carried out using the PROCESS macro for SPSS [48]. The bias-corrected $95 \%$ confidence interval (CI) was calculated with a 5000 bootstrapping resample. Firstly, we tested whether the association between job control and work ability was mediated by SOC strategies using model 4 (see Figure 1). If the $95 \%$ CI of the indirect effect (path $a^{*} b$ ) did not contain 0 , it indicated that the mediating effect was significant.

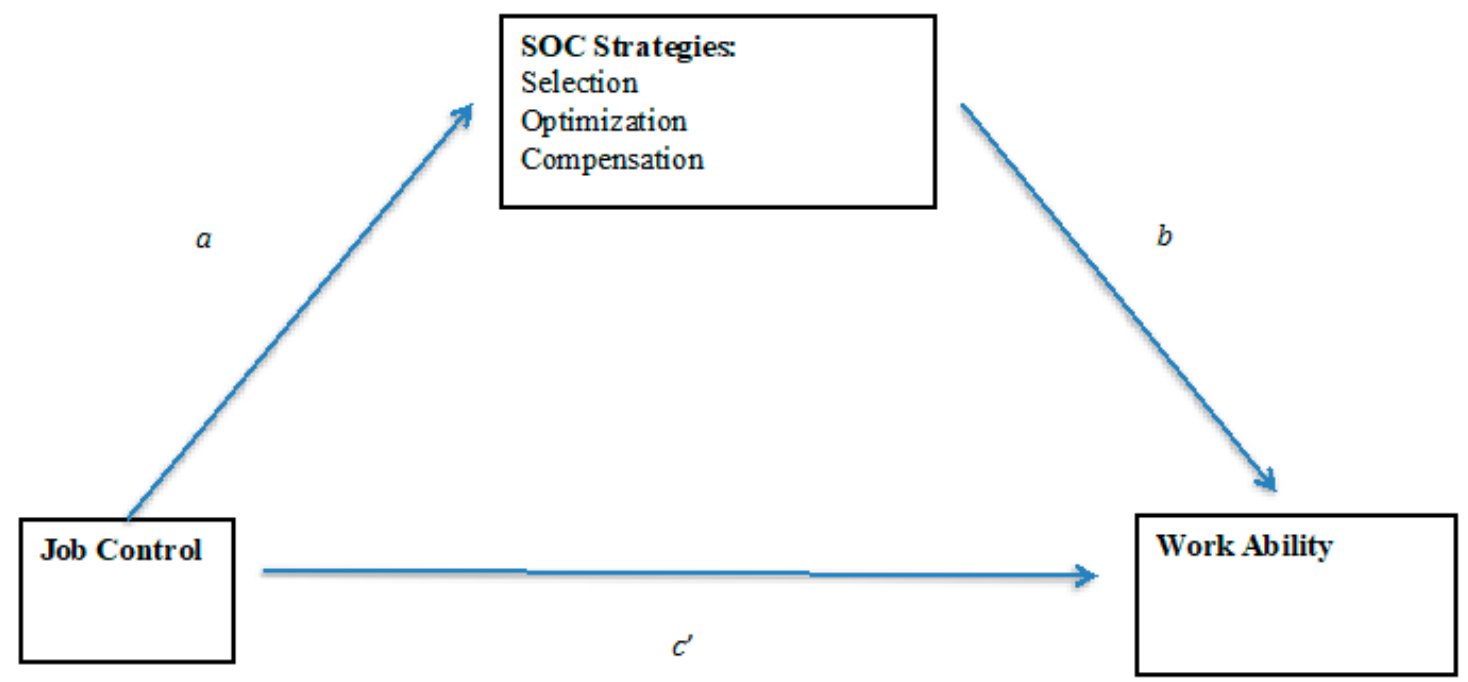

Figure 1. Schematic model of selection, optimization and compensation (SOC) strategies as a mediator between job control and work ability (Andrew Hayes's moderation-mediation model, Model 4). 
Next, Model 59 was used to examine the moderated mediation effect; that is, whether age moderates the direct and indirect effects of job control on work ability. More specifically, age moderates the following: (1) the relationship between job control and work ability; (2) the relationship between job control and elective selection, loss-based selection, optimisation, or compensation; (3) the relationship between elective selection, loss-based selection, optimisation, or compensation and work ability (see Figure 2). Likewise, if the $95 \% \mathrm{CI}$ of the interaction did not contain 0 , the moderated mediation effect was significant. In addition, a control variable (educational level) was included in the model as a covariate.

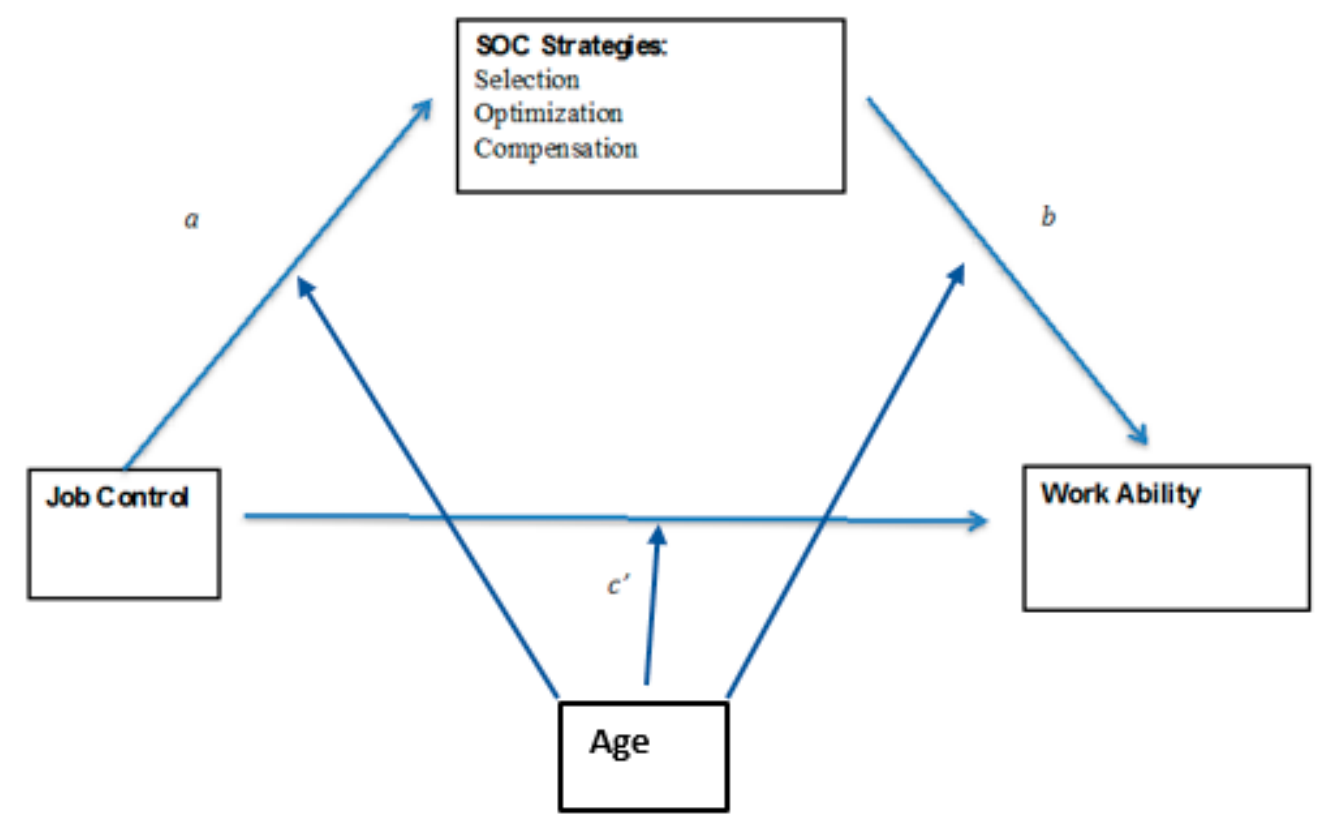

Figure 2. Schematic model of age as a moderator of the mediation model (Andrew Hayes's moderation-mediation model, Model 59).

\section{Results}

\subsection{Sociodemographic Working Characteristics and Work Ability}

The sociodemographic characteristics are indicated in Table 1. In total, 1704 workers were contacted. The mean age of the sample was 52.5 (SD = 7.49); $1104(64.8 \%)$ workers were female and 600 $(35.2 \%)$ were men. Of the participants, $64.4 \%$ were married or cohabitants and $35.6 \%$ were unmarried or widowers, and $68.4 \%$ had offspring, while $31.6 \%$ had no children. Most of the participants had a high school diploma (53.4\%), while the number of graduates was lower $(37.7 \%)$.

Most of the participants had full-time working hours (91\%), and only $9 \%$ worked part-time. The workers considered by the study had an average seniority of service of 24.5 years (SD $=10.48$ ).

The mean score of the WAI was 36.14 (SD = 5.94), which appears to be moderate (score: 7-27: bad; 28-36: moderate; 37-43: good; 44-49: very good), according to the manual [36].

If considered in association with sociodemographic characteristics, the correlations indicated that the work ability was significantly lower with increasing age $(r=-0.35 ; p=0.010)$. Moreover, the $t$-test showed that WAI was significantly higher among graduates when compared to workers with a lower educational qualification $(t=6.88 ; p=0.000)$. 
Table 1. Sociodemographic (age, gender, marital status, offspring, educational level), working hours, and the distribution of work ability index for administrative workers: Frequencies, work ability index, t-test or F ratio of ANOVA.

\begin{tabular}{|c|c|c|c|c|}
\hline & \multicolumn{4}{|c|}{ Administrative Workers } \\
\hline & Frequencies(\%) & Work Ability Index & $\mathbf{F} / \mathbf{t}$ & $p$ \\
\hline Age & & & 44.361 & 0.000 \\
\hline$<49$ & $473(27.8 \%)$ & 39.17 & & \\
\hline $50-55$ & $499(29.3 \%)$ & 36.28 & & \\
\hline $56-59$ & $470(27.6 \%)$ & 33.84 & & \\
\hline$>60$ & $262(15.4 \%)$ & 34.41 & & \\
\hline Gender & & & 1.319 & 0.187 \\
\hline Female & $1104(64.8 \%)$ & 35.98 & & \\
\hline Male & $600(35.2 \%)$ & 36.54 & & \\
\hline Marital status & & & -0.988 & 0.323 \\
\hline Married & $1097(64.4 \%)$ & 36.29 & & \\
\hline Unmarried & $607(35.6 \%)$ & 35.89 & & \\
\hline Offspring & & & 1.223 & 0.222 \\
\hline Yes & $1165(68.4 \%)$ & 35.98 & & \\
\hline No & $539(31.6 \%)$ & 36.49 & & \\
\hline Educational levels & & & 6.885 & 0.000 \\
\hline Middle or High school & $1026(62.3 \%)$ & 35.06 & & \\
\hline College or above & $621(37.7 \%)$ & 37.85 & & \\
\hline Working Hours & & & -1.557 & 0.120 \\
\hline Full-time & $1550(91.0 \%)$ & 36.25 & & \\
\hline Part-time & $114(9.0 \%)$ & 35.27 & & \\
\hline
\end{tabular}

\subsection{Bivariate Correlations among All Variables}

Table 2 provides the correlations of the variables studied.

The correlations indicated that job control was positively related to work ability $(r=0.204$; $p=0.000$ ). Optimisation and compensation were positively related to work ability (optimisation: $\mathrm{r}=0.215 ; p=0.000$ and compensation: $\mathrm{r}=0.156 ; p=0.000$ ), while loss-based selection was negatively related to age $(\mathrm{r}=-0.091 ; p=0.000)$. In addition, job control had a significantly positive relation to optimisation $(\mathrm{r}=0.205 ; p=0.000)$, compensation $(\mathrm{r}=0.143 ; p=0.000)$, and age $(\mathrm{r}=0.101 ; p=0.000)$, and a negative relation to elective selection $(\mathrm{r}=-0.063 ; p=0.010)$.

Table 2. Bivariate correlation among job control, work ability, SOC strategies, and age for administrative workers.

\begin{tabular}{cccccccc}
\hline & $\mathbf{1}$ & $\mathbf{2}$ & $\mathbf{3}$ & $\mathbf{4}$ & $\mathbf{5}$ & $\mathbf{6}$ & $\mathbf{7}$ \\
\hline 1. Job control & 1 & $-0.063^{*}$ & -0.005 & $0.205^{* *}$ & $0.143^{* *}$ & $0.101^{* *}$ & $0.204^{* *}$ \\
2. Elective Selection & $0.063^{*}$ & 1 & $0.530^{* *}$ & $0.383^{* *}$ & $0.358^{* *}$ & -0.033 & 0.062 \\
3. Loss based selection & -0.005 & $0.530^{* *}$ & 1 & $0.272^{* *}$ & $0.423^{* *}$ & $-0.091^{* *}$ & 0.049 \\
4. Optimisation & $0.205^{* *}$ & $0.383^{* *}$ & $0.272^{* *}$ & 1 & $0.587^{* *}$ & -0.039 & $0.215^{* *}$ \\
5. Compensation & $0.143^{* *}$ & $0.358^{* *}$ & $0.423^{* *}$ & $0.587^{* *}$ & 1 & -0.036 & $0.158^{* *}$ \\
6. Age & $0.101^{* *}$ & -0.033 & $-0.091^{* *}$ & -0.039 & -0.036 & 1 & $-0.353^{* *}$ \\
7. Work ability & $0.204^{* *}$ & 0.062 & 0.049 & $0.215^{* *}$ & $0.158^{* *}$ & $-0.3533^{* *}$ & 1 \\
\hline
\end{tabular}

${ }^{*} p<0.05 ;{ }^{* *} p<0.001$.




\subsection{Mediation Analyses}

Considering all SOC strategies, the results of mediation analyses showed that the total effect (path $c)$ of job control on work ability was significant $(B=0.275 ; p=0.000)$. The significant coefficient of path $a(\mathrm{~B}=0.010 ; p=0.003)$ indicated positive associations between job control and SOC strategies. Besides, the point estimate of the indirect effect (path $a^{*} b$ ) between job control and work ability through SOC strategies was $0.020(\mathrm{SE}=0.01$ ), and the $95 \%$ bias-corrected bootstrap confidence interval was 0.002 to 0.043 , which indicated that the indirect effect of job control on work ability was statistically significant (Table 3).

Below, the SOC strategies are considered separately:

(1a) Elective Selection. The results of mediation analyses showed that the total effect (path $c$ ) of job control on work ability was significant $(\mathrm{B}=0.280 ; p=0.000)$, and path $a(\mathrm{~B}=-0.011 ; p=0.010)$ and path $b(\mathrm{~B}=0.929 ; p=0.017)$ showed significant coefficients, which indicated negative associations between job control and elective selection, and positive associations between elective selection and work ability. The direct effect of job control on work ability (path $c^{\prime}=0.290, p=0.000$ ) was also significant, but the indirect effect of job control on work ability through elective selection was not (Table 3). Data indicated that elective selection did not mediate the relationship between job control and work ability. Therefore, mediation moderation analysis was not carried out.

(1b) Loss-based Selection. The results of mediation analyses showed that the total effect and the direct effect of job control on work ability were significant (path $c$ : $\mathrm{B}=0.280 ; p=0.000$; path $c^{\prime}=0.279$, $p=0.000$ ). However, there was no statistically significant coefficient of path $b$ or path $a$. Also, the indirect effect (path $a^{*} b$ ) between job control and work ability through selection was not significant. Data indicated that loss-based selection did not mediate the relationship between job control and work ability. Therefore, mediation moderation analysis was not carried out.

(2) Optimisation. The results of the mediation analyses confirmed that the total effect (path $c$ ) of job control on work ability was significant $(B=0.280 ; p=0.000)$ and showed a significant coefficient of path $a(\mathrm{~B}=0.028 ; p=0.000)$ and path $b(\mathrm{~B}=2.002 ; p=0.000)$, indicating positive associations between job control and optimisation, as well as between optimisation and work ability. Besides, the point estimate of the indirect effect (path $a^{*} b$ ) between job control and work ability through optimisation was 0.057 ( $\mathrm{SE}=0.016$ ), and the $95 \%$ bias-corrected bootstrap confidence interval was 0.029 to 0.090 , which indicated that the indirect effect of job control on work ability was statistically significant. In addition, the direct effect of job control on work ability (path $c^{\prime}=0.223, p=0.000$ ) was also significant. Data indicated that optimisation partially mediated the relationship between job control and work ability (Table 3).

(3) Compensation. The results of mediation analyses confirmed that the total effect (path $c$ ) of job control on work ability was significant $(B=0.280 ; p=0.000)$ and showed a significant coefficient of path $a(\mathrm{~B}=0.017 ; p=0.004)$ and path $b(\mathrm{~B}=1.595 ; p=0.000)$, indicating positive associations between job control and compensation, and between compensation and work ability. Besides, the point estimate of the indirect effect (path $a^{*} b$ ) between job control and work ability through compensation was $0.028(\mathrm{SE}=0.011)$, and the $95 \%$ bias-corrected bootstrap confidence interval was 0.009 to 0.053 , which indicated that the indirect effect of job control on work ability was statistically significant. In addition, the direct effect of job control on work ability (path $c^{\prime}=0.252$, $p=0.000$ ) was also significant, indicating that compensation partially mediated the relationship between job control and work ability (Table 3). 
Table 5. Moderated mediation analyses with optimisation: The moderation effect of age on the relationship between job control and work ability, job control and optimisation, and optimisation and work ability.

\begin{tabular}{cccccc}
\hline Variable & B & SE & t & LLCI & ULCI \\
\hline Outcome variable: Optimisation & & & & \\
\hline Job control & -0.008 & 0.029 & -0.276 & -0.064 & 0.048 \\
Age & $-0.015^{*}$ & 0.007 & -0.2 .089 & -0.030 & -0.001 \\
Job control*age & 0.001 & 0.001 & 1.339 & -0.0003 & 0.002 \\
\hline Outcome variable: WAI & & & & & \\
\hline Job control & -0.332 & 0.307 & -0.1 .083 & -0.935 & 0.270 \\
Optimisation & -3.104 & 2.426 & -0.1 .279 & -0.7 .866 & 1.658 \\
Age & -0.621 & 0.119 & -0.5 .217 & -0.855 & -0.387 \\
Job control*age & $0.012^{*}$ & 0.006 & 2.085 & 0.007 & 0.024 \\
Optimisation*age & $0.090^{*}$ & 0.046 & 1.971 & 0.004 & 0.181 \\
\hline
\end{tabular}

Note: controlling for educational level ${ }^{*} p<0.05$.

Table 6 shows that the direct impact of job control on work ability is stronger as age increases (44 years old: $\mathrm{B}=0.203 ; 95 \% \mathrm{CI}: 0.070,0.327 ; p=0.002 ; 55$ years old: $\mathrm{B}=0.337 ; 95 \%$ CI: $0.229,0.427$; $p=0.000 ; 60$ years old: $\mathrm{B}=0.398 ; 95 \% \mathrm{CI}: 0.257,0.516 ; p=0.000)$. Similarly, the direct impact of optimisation on work ability was stronger as age increased (44 years old: $\mathrm{B}=0.877 ; 95 \% \mathrm{CI}:-0.143$, $1.898 ; p=0.092 ; 55$ years old: $\mathrm{B}=1.873 ; 95 \% \mathrm{CI}: 1.136,2.609 ; p=0.000 ; 60$ years old: $\mathrm{B}=2.325 ; 95 \% \mathrm{CI}$ : $1.343,3.307 ; p=0.000)$. The indirect effect of job control on work ability through optimisation was also stronger as age increased ( 44 years old: $\mathrm{B}=0.021 ; 95 \% \mathrm{CI}:-0.005,0.051 ; 55$ years old: $\mathrm{B}=0.060$; $95 \%$ CI: $0.029,0.097 ; 60$ years old: $\mathrm{B}=0.083 ; 95 \%$ CI: $0.035,0.144)$.

Table 6. Conditional direct and indirect effect of job control on work ability at different ages, with Optimisation as mediator: (1) Conditional direct effect of job control on work ability at different ages; (2) conditional direct effect of optimisation on work ability at different ages; and (3) conditional indirect effect at different ages.

\begin{tabular}{lcccc}
\hline & B & SE & LLCI & ULCI \\
\hline \multicolumn{5}{c}{ Conditional direct effect (focal predict: job control) } \\
\hline 44 years old & 0.203 & 0.664 & 0.073 & 0.333 \\
55 years old & 0.337 & 0.510 & 0.237 & 0.437 \\
60 years old & 0.398 & 0.671 & 0.266 & 0.530 \\
\hline \multicolumn{5}{c}{ Conditional direct effect (focal predict: optimisation) } \\
\hline 44 years old & 0.877 & 0.520 & -0.143 & 1.898 \\
55 years old & 1.873 & 0.375 & 1.136 & 2.609 \\
60 years old & 2.325 & 0.500 & 1.343 & 3.307 \\
\hline \multicolumn{5}{c}{ Conditional indirect effect } \\
\hline 44 years old & 0.021 & 0.014 & -0.005 & 0.051 \\
55 years old & 0.060 & 0.017 & 0.029 & 0.097 \\
60 years old & 0.083 & 0.027 & 0.035 & 0.144 \\
\hline
\end{tabular}

(2) Compensation. Tables 7 and 8 show that age only moderated the direct effect of job control on work ability (job control*age: $\mathrm{B}=0.014 ; p=0.014$ ). The direct impact of job control on work ability was stronger as age increased (44 years old: $\mathrm{B}=0.213 ; 95 \% \mathrm{CI}: 0.083,0.344 ; p=0.001 ; 55$ years old: $\mathrm{B}=0.371 ; 95 \%$ CI: $0.272,0.470 ; p=0.000 ; 60$ years old: $\mathrm{B}=0.442 ; 95 \% \mathrm{CI}: 0.313,0.573 ; p=0.000$ ). Similarly, the indirect effect of job control on work ability through compensation was stronger as age increased ( 44 years old: $\mathrm{B}=0.016 ; 95 \% \mathrm{CI}:-0.0009,0.040 ; 55$ years old: $\mathrm{B}=0.028 ; 95 \% \mathrm{CI}$ : $0.009,0.056 ; 60$ years old: $B=0.035 ; 95 \% \mathrm{CI}: 0.007,0.077)$. 
Table 7. Moderated mediation analyses with Compensation: The moderation effect of age on the relationship between job control and work ability, job control and compensation, and compensation and work ability.

\begin{tabular}{cccccc}
\hline Variable & $\mathbf{B}$ & $\mathbf{S E}$ & $\mathbf{t}$ & LLCI & ULCI \\
\hline Outcome variable: Compensation & & & & \\
\hline Job control & -0.004 & 0.028 & -0.131 & -0.058 & 0.051 \\
Age & -0.009 & 0.007 & -1.225 & -0.023 & 0.005 \\
Job control*age & 0.0004 & 0.001 & 0.802 & -0.001 & 0.001 \\
\hline Outcome variable: WAI & & & & & \\
\hline Job control & -0.417 & 0.306 & -1.362 & -1.019 & 0.184 \\
Compensation & -0.393 & 2.664 & -0.147 & -5.621 & 4.835 \\
Age & $-0.514^{* *}$ & 0.116 & -4.409 & -0.742 & -0.285 \\
Job control*age & $0.014^{*}$ & 0.006 & 2.462 & 0.003 & 0.026 \\
Compensation*age & 0.033 & 0.049 & 0.668 & -0.064 & 0.130 \\
\hline
\end{tabular}

Note: controlling for educational level ${ }^{* *} p<0.001$ and ${ }^{*} p<0.05$.

Table 8. Conditional direct and indirect effect of job control on work ability at different ages, with Compensation as mediator: (1) Conditional direct effect of job control on work ability at different ages; (2) conditional direct effect of compensation on work ability at different ages; and (3) conditional indirect effect at different ages.

\begin{tabular}{|c|c|c|c|c|}
\hline & B & SE & LLCI & ULCI \\
\hline \multicolumn{5}{|c|}{ Conditional direct effect } \\
\hline 44 years old & 0.213 & 0.066 & 0.083 & 0.344 \\
\hline 55 years old & 0.371 & 0.050 & 0.272 & 0.470 \\
\hline 60 years old & 0.443 & 0.066 & 0.313 & 0.573 \\
\hline \multicolumn{5}{|c|}{ Conditional indirect effect } \\
\hline 44 years old & 0.016 & 0.011 & -0.001 & 0.040 \\
\hline 55 years old & 0.028 & 0.012 & 0.009 & 0.056 \\
\hline 60 years old & 0.035 & 0.018 & 0.007 & 0.077 \\
\hline
\end{tabular}

\section{Discussion}

This study investigated the work ability of administrative workers, examined the mediating role of SOC strategies (also considered separately) among job control and work ability, and explored the relationship between job control, optimisation and compensation, age, and work ability via moderated mediation models.

The findings indicate that job control, SOC strategies, and age were correlated to work ability, but the effects of these factors were different. To sum up the hypotheses: $\mathrm{H} 1$ has been confirmed, and job control was positively related to work ability. $\mathrm{H} 2$ has been partially confirmed. The use of elective selection, optimisation, and compensation at work was positively related to work ability; however, loss-based selection was not associated with work ability. $\mathrm{H} 3$ has been partially confirmed. Job control was positively related to use of optimisation and compensation. However, a negative relationship between job control and elective selection emerged, and there was no relationship between job control and loss-based selection. H4 has been partially confirmed. Optimisation and compensation strategies mediated the association between job control and work ability [39]. Conversely, selection did not mediate the relationship between job control and work ability. H5 has been partially confirmed. The direct effect of job control on work ability was moderated by age, and also, the direct effect of optimisation on work ability was moderated by age. Both the direct effect of job control on work ability and the indirect effect of job control on work ability, through optimisation and compensation strategies, were stronger as age increased. 
In the present study, the mean score of work ability was 36.1 (SD \pm 5.9$)$, which was lower if compared with the scores that were found in previous studies on work ability among administrative workers. For example, Godinho et al. [14] observed an average WAI among the administrative workers of 41.6 (SD \pm 5.1) in Brazil. Similarly, in the Netherlands, Schouten et al. [49] and Reeuwijk et al. [50] found average WAIs of $42.7(\mathrm{SD} \pm 4.7)$ and $42.1(\mathrm{SD} \pm 4.8)$ among office workers. In Italy, Costa and Camerino [51] observed an average WAI of 42 (SD \pm 3.9 ) among clerks. This result was in line with the mean age, which was higher than that found in other studies- 52 years old in our study, 45 years old in that of Godinho et al. [14], 47.8 for the case of Schouten et al. [49], and only 43.3 years for the study of Reeuwijk et al. [50]. In our study, the average age was higher, which could explain the lower WAI [52]. Another explanation could be based on gender. In our study, the workers were almost completely female, and previous studies found that work ability of women was generally lower than that of men [14], probably because they perform two sets of tasks: professional and domestic [53].

Given these problems (significant ageing and a low WAI), it is necessary to consider the possible resources available to support the work ability of administrative workers in the public sector. Our results revealed a positive correlation between job control and work ability, which was consistent with previous studies [8-10,26,29,30,38]. This result confirmed that job control is a crucial resource for work ability.

In addition, the use of SOC strategies, especially optimisation and compensation, was an aid for work ability, according to the studies of Müller et al. [39,54], Weigl et al. [30], and Weber et al. [29], confirming that the use of "successful ageing strategies", such as SOC, are conducive to the psychological capability of administrative workers to perform their work.

Results further point to a positive relation between job control and optimisation and compensation strategies. More job control was associated with the use of optimisation and compensation strategies at work. This finding confirmed the studies of Müller et al. [39] and Weigl et al. [30], which suggested that the use of SOC strategies requires favourable working conditions, especially suitable job design and job autonomy. Job control provides employees with the discretion to select their goals and to invest available resources on the basis of their preferences, rather than following rigid work routines that leave little space for SOC strategy use [33].

The current study highlighted optimisation and compensation strategies as a partial form of mediation between job control and work ability, which may reveal the underlying mechanism through which job control might indirectly influence work ability. In this way, job control would favour the adoption of optimisation and compensation strategies, indirectly protecting work ability. Also, the study by Müller et al. [39] provided support concerning SOC strategies as a form of mediation between job control and work ability.

In contrast to other studies $[35,39]$, we did not use the unique dimension of SOC strategies, but instead we used elective selection, loss-based selection, optimisation, and compensation separately, based on a recent study by Segura-Camacho et al. [40]. The authors underlined that while most studies used overall SOC or three strategies (selection, optimisation, and compensation), few studies included four dimensions $[33,40]$. From this viewpoint, our study underlined that selection strategies, especially loss-based selection, were not very effective in protecting work ability. This is in line with Zacher et al.'s findings [38], which showed that optimisation and compensation, but not selection, had positive effects on work engagement, and the study by Segura-Camacho et al. [40], which found optimisation and compensation to have a moderating role (in contrast with elective and loss-based selection) in the relationship between task characteristics and employee well-being. Similarly, Demerouti et al. [55] found that compensation was the most successful strategy in buffering the negative associations of disengagement with supervisor-rated task performance, and both disengagement and exhaustion with supervisor-rated adjustment to change. Weber et al. [29] observed that only compensation had a positive, albeit weak, effect on work ability.

However, we can imagine that working as an employee in a public context makes it difficult to select the objectives of your work, while it is easier to optimise your resources and to compensate 
for any limits. For this reason, selection does not mediate the relationship between control and work ability.

Moreover, Müller et al. [39] and Von Bonsdorff et al. [35] revealed the moderating effect of age on the association between SOC strategies and work ability (Müller et al. observed a positive moderating effect, while Von Bonsdorff et al. observed a negative moderating effect). We found a positive moderating effect of age on the association between job control and work ability. This means that older respondents benefit more from job control in maintaining their work ability [56]. According to this, the direct and indirect effects of job control on work ability were stronger as age increased, confirming one of the basic propositions of the SOC model [31], which underlines that older workers, in particular, benefit from SOC strategies [57].

The study has several practical implications. First of all, to support the work of administrative workers, it is necessary to redefine the work and promote job control. In addition, the workers should be acquainted with and trained using the SOC model and SOC strategies at work, especially regarding optimisation and compensation. These are essential to sustain work ability, and the results, in fact, indicated that both job design intervention (job control promotion) and SOC training should have a positive effect on work ability [58]. Consequently, individual strategies of optimisation and compensation could be considered as psychological resources useful for supporting work ability [59]. This data confirm that the occupational interventions based on SOC strategies might contribute to successful ageing at work, despite the fact that SOC interventions at work are scarce [60]. However, job control seems to be the precondition for the application of optimisation and compensation strategies at work. As a result, job control should contribute to the effectiveness of SOC training [39]. However, our research considered the four sub-dimensions of SOC separately, providing more specific information on the effectiveness of each dimension. Job support interventions should develop job control, foster optimisation, and increase compensation. Furthermore, our study involved administrative workers, who are not often considered in studies on work ability and the use of SOC strategies. In view of the very large number of older workers who perform administrative tasks in public offices, we believe that it is important to involve this population in studies on the sustainability of work.

The study had several limitations. First, it used a cross-sectional design, so these results were only a preliminary evaluation of the hypothesised cause-effect relations. There is evidence in the literature that led us to assume that SOC strategies impact work ability; however, it was also possible that workers with better work ability had more resources, and therefore, were better able to use SOC strategies. Second, the age effect may be limited due to differences between birth cohorts and it may not necessarily reflect the development of ageing [39]. Third, potential healthy-worker effects could have biased our findings. The workers with impaired work ability might have retired earlier. Fourth, the study used exclusively self-reported data. Finally, we did not consider the firm size, which could influence the dimensions investigated. Empirical researchers consider firm size an important characteristic that can affect the results [61].

To overcome these limitations, future studies should apply cross-lagged or longitudinal designs to test cause-effect relations clearly and use a multi-method design to overcome the limits of self-reported data. Moreover, future study should apply methods to address endogeneity bias (e.g., using the generalised method of moments, GMM) [62].

Author Contributions: I.S. prepared the design and the manuscript of this study. G.G. and S.V. substantially contributed to data analysis and interpretation. D.C. is the PI of the whole study project substantially contributing to data interpretation and critically revised the final form of the manuscript.

Funding: This research was funded by Municipality of Turin, grant number COND_CT_RIC_17_02 of 28/11/2017.

Conflicts of Interest: No potential conflict of interest was reported by the authors. 


\section{References}

1. Assefa, N.L.; Zenebe, D.; Alemu, W.H.W.; Anbesse, D.H. Prevalence and associated factors of computer vision syndrome among bank workers in Gondar City, northwest Ethiopia. Clin. Opt. 2017, 9, 67-76. [CrossRef]

2. Eurofound. 2018. Available online: https://www.eurofound.europa.eu/topic/sustainable-work (accessed on 27 November 2018).

3. Tuomi, K.; Eskelinen, L.; Toikkanen, J.; Jarvinen, E.; Ilmarinen, J.; Klockars, M. Work load and individual factors affecting work ability among aging municipal employees. Scand. J. Work Environ. Health 1991, 17, 128-134. [PubMed]

4. Tuomi, K.; Huuhtanen, P.; Nykyri, E.; Ilmarinen, J. Promotion of work ability, the quality of work and retirement. Occup. Med. 2001, 51, 318-324. [CrossRef]

5. Camerino, D.; Conway, P.M.; Van der Heijden, B.I.; Estryn-Behar, M.; Consonni, D.; Gould, D.; Hasselhorn, H.M. NEXT-Study Group. J. Adv. Nurs. 2006, 56, 542-552. [CrossRef] [PubMed]

6. Lin, S.; Wang, Z.; Wang, M. Work ability of workers in western China: Reference data. Occup. Med. 2006, 56, 89-93. [CrossRef]

7. Monteiro, M.S.; Ilmarinen, J.; Filho, H.R.C. Work ability of workers in different age groups in a public health institution in Brazil. Int. J. Occup. Saf. Ergon. 2006, 12, 417-427. [CrossRef] [PubMed]

8. Van den Berg, T.I.J.; Robroek, S.J.; Plat, J.F.; Koopmanschap, M.A.; Burdorf, A. The importance of job control for workers with decreased work ability to remain productive at work. Int. Arch. Occup. Environ. Health 2011, 84, 705-712. [CrossRef] [PubMed]

9. Van den Berg, T.I.J.; Elders, L.A.M.; De Zwart, B.C.H.; Burdorf, A. The effect of work related and individual factors on the Work Ability Index: A systematic review. Occup. Ennviron. Med. 2009, 66, 211-220. [CrossRef]

10. Converso, D.; Sottimano, I.; Guidetti, G.; Loera, B.; Cortini, M.; Viotti, V. Aging and Work Ability: The Moderating Role of Job and Personal Resources. Frontiers 2018, 8, 1-12. [CrossRef]

11. Ilmarinen, J.; Ilmarinen, V. Work ability and aging. In Facing the Challenges of a Multi-Age Workforce: A Use-Inspired Approach; Finkelstein, L.M., Truxillo, D.M., Fraccaroli, F., Kanfer, R., Eds.; Routledge: New York, NY, USA, 2015; pp. 134-156.

12. Goedhard, R.G.; Goedhard, W.J.A. Work ability and perceived work stress. Int. Congr. Ser. 2005, 1280, 79-83. [CrossRef]

13. Alavinia, S.M.; Molenaar, D.; Burdorf, A. Productivity loss in the workforce: Associations with health, work demands, and individual characteristics. Am. J. Ind. Med. 2009, 52, 49-56. [CrossRef] [PubMed]

14. Godinho, M.R.; Greco, M.N.; Teixeira, M.T.B.; Teixeira, L.R.; Guerra, M.R.; Chaoubach, A. Work ability and associated factors of Brazilian technical-administrative workers in education. BMC Res. Notes 2016, 9, 1. [CrossRef]

15. Eurostat. 2016. Available online: http://ec.europa.eu/eurostat/statisticsexplained/index.php/Labour_ market_and_Labour_force_survey_(LFS)_statistics (accessed on 10 January 2019).

16. European Commission. 2015. Available online: https://ec.europa.eu/digital-single-market/en/news / quality-public-administration-toolbox-practitioners (accessed on 10 January 2019).

17. ARAN. 2018. Available online: http://www.aranagenzia.it/statistiche-e-pubblicazioni (accessed on 17 January 2019).

18. Demerouti, E.; Bakker, A.B.; Nachreiner, F.; Schaufeli, W.B. The job demands-resources model of burnout. J. Appl. Psychol. 2001, 86, 499-512. [CrossRef] [PubMed]

19. Karasek, R.A. Job demands, job decision latitude, and mental strain. Implication for job redesign. Adm. Sci. Q. 1979, 24, 285. [CrossRef]

20. McGonagle, A.K.; Barnes-Farrell, J.L.; Di Milia, L.; Fischer, F.M.; Hobbs, B.B.B.; Iskra-Golec, I.; Kaliterna, L. Demands, resources and work ability: A cross-national examination of health care workers. Eur. J. Work Organ. Psychol. 2014, 23, 830-846. [CrossRef]

21. Viotti, S.; Guidetti, G.; Loera, B.; Martini, M.; Sottimano, I.; Converso, D. Stress, work ability, and an aging workforce: A study among women aged 50 and over. Int. J. Stress Manag. 2017, 24 (Suppl. S1), 98-121. [CrossRef] 
22. Zacher, H.; Heusner, S.; Schmitz, M.; Zwierzanska, M.M.; Frese, M. Focus on opportunities as a mediator of the relationships between age, job complexity, and work performance. J. Vocat. Behav. 2010, 76, 374-386. [CrossRef]

23. Truxillo, D.M.; Cadiz, D.M.; Rineer, J.R.; Zaniboni, S.; Fraccaroli, F. A lifespan perspective on job design: Fitting the job and the workers to promote job satisfaction, engagement and performance. Org. Psychol. Rev. 2012, 2, 340-360. [CrossRef]

24. Viotti, S.; Converso, D. Relationship between job demands and psychological outcomes among nurses: Does skill discretion matter? Int. J. Occup. Med. Environ. Health 2016, 29, 439-460. [CrossRef]

25. Martini, M.; Converso, D. Lo studio del burnout in sanità: rapporto coi pazienti e relazione lavoro-famiglia come richieste e risorse. Giornale Italiano di Medicina del Lavoro ed Ergonomia 2012, 34, 41-50.

26. Sottimano, I.; Viotti, S.; Guidetti, G.; Converso, D. Protective factors for work ability in preschool teachers. Occup. Med. 2017, 67, 301-304. [CrossRef] [PubMed]

27. Zaniboni, S.; Truxillo, D.M.; Fraccaroli, F. Differential effects of task variety and skill variety on burnout and turnover intentions for older and younger workers. Eur. J. Work Organ. Psychol. 2013, 22, 306-317. [CrossRef]

28. Loera, B.; Gattino, S.; Converso, D. Giustizia organizzativa, supporto sociale e burnout tra lavoratori della Sanità: effetti diretti e di moderazione. Psicologia della Salute 2013, 1, 27-48. [CrossRef]

29. Weber, J.; Müller, A.; Stiller, L.; Borchart, D. Prognostic effects of selection, optimization and compensation strategies on work ability: Results from the representative lidA cohort study on work, age, and health in Germany. Int. Arch. Occup. Environ. Health 2018, 91, 1061-1071. [CrossRef] [PubMed]

30. Weigl, M.; Müller, A.; Horning, S.; Zacher, H.; Angerer, P. The moderating effects of job control and selection, optimization, and compensation strategies on the age-work ability relationship. J. Organ. Behav. 2013, 34, 607-628. [CrossRef]

31. Baltes, P.B.; Baltes, M.M. Psychological perspectives on successful aging: The model of selective optimization with compensation. In Successful Aging, Perspective from the Behavioral Science; Baltes, P.B., Baltes, M.M., Eds.; Cambridge University Press: New York, NY, USA, 1990; pp. 1-34.

32. Baltes, B.B.; Rudolph, C.W. The theory of selection, optimization, and compensation. In The Oxford Handbook of Retirement; Wang, M., Ed.; Oxford University Press: New York, NY, USA, 2013; pp. 88-101.

33. Moghimi, D.; Zacher, M.; Scheibe, S.; Van Yperen, N.W. The selection, optimization, and compensation model in the work context: A systematic review and meta-analysis of two decades of research. J. Organ. Behav. 2017, 38, 247-275. [CrossRef]

34. Freund, A.M.; Baltes, P.B. Life-management strategies of selection, optimization and compensation: Measurement by self-report and construct validity. J. Personal. Social Psychol. 2002, 82, 642-662. [CrossRef]

35. Von Bordorff, M.E.; Von Bordorff, M.B.; Zhou, Z.E.; Kauppinen, M.; Miettinen, M.; Rantanen, T.; Vanhala, S. Organizational justice, selection, optimization with compensation and nurses' work ability. JOEM 2014, 56, 326-330.

36. Weigl, M.; Müller, A.; Hornung, S.; Leidenberger, M.; Heiden, B. Job resources and work engagement: The contributing role of selection, optimization and compensation strategies at work. J. Labour Mark. Res. 2014, 47, 299-312. [CrossRef]

37. Abraham, J.D.; Hansson, R.O. Successful aging at work: An applied study of selection, organization, optimization, and compensation through impression management. J. Gerontol. Psychol. Sci. Soc. Sci. 1995, 50B, 94-103. [CrossRef]

38. Zacher, H.; Chan, F.; Bakker, A.B.; Demerouti, E. Selection, optimization, and compensation strategies: Interactive effects on daily work engagement. J. Vocat. Behav. 2015, 87, 101-107. [CrossRef]

39. Müller, A.; Weigl, M.; Heiden, B.; Glaser, J.; Angerer, P. Promoting work ability and well-being in hospital nursing: The interplay of age, job control and successful ageing strategies. Work 2012, 41, 5137-5144.

40. Segura-Camacho, A.; Garcì-Orozco, J.J.; Topa, G. Sustainable and Healthy Organizations Promote Employee Well-Being: The Moderating Role of Selection, Optimization, and Compensation Strategies. Sustainability 2018, 10, 3411. [CrossRef]

41. Di Fabio, A. The psychology of sustainability and sustainable development for well-being in organizations. Front. Psychol. 2017, 8, 1534. [CrossRef] [PubMed]

42. Di Fabio, A. Positive Healthy Organizations: Promoting Well-Being, Meaningfulness, and Sustainability in Organizations. Front. Psychol. 2017, 8, 1938. [CrossRef] [PubMed] 
43. Di Fabio, A.; Rosen, M.A. Opening the Black Box of Psychological Processes in the Science of Sustainable Development: A New Frontier. Eur. J. Sustain. Dev. Res. 2018, 2, 47. [CrossRef]

44. Sottimano, I.; Guidetti, G.; Converso, D.; Viotti, S. We cannot be “forever young," but our children are: A multilevel intervention to sustain nursery school teachers' resources and well-being during their long work life cycle. PLoS ONE 2018, 13, e0206627. [CrossRef]

45. Tuomi, K.; Ilmarinen, J.; Jahkola, A.; Katajarinne, L.; Tulkki, A. Work Ability Index, 2nd ed.; Finnish Institute of Occupational Health: Helsinki, Finland, 1998.

46. Freund, A.M.; Baltes, P.B. The orchestration of selection, optimization and compensation: An action-theoretical conceptualization of a theory of developmental regulation. In Control of Human Behavior, Mental Processes, and Consciousness; Perrig, W.J., Grob, A., Eds.; Lawrence Erlbaum: Mahwah, NJ, USA, 2000; pp. 35-58.

47. Baltes, P.B.; Baltes, M.M.; Freund, A.; Lang, F. The Measurement of Selection, Optimization, and Compensation (SOC) by Self Report: Technical Report; Max Planck Institute for Human Development: Berlin, Germany, 1999.

48. Hayes, A.F. PROCESS: A Versatile Computational Tool for Observed Variable Mediation, Moderation, and Conditional Process Modeling [White Paper]. 2012. Available online: http:/ / www.afhayes.com/public/ process2012.pdf (accessed on 20 November 2018).

49. Schouten, L.S.; Joling, C.I.; van der Gulden, J.W.J.; Heymans, M.W.; Bültmann, U.; Roelen, C.A.M. Screening manual and office workers for risk of long-term sickness absence: Cut-off points for the Work Ability Index. Scand. J. Work Environ. Health 2015, 41, 36-42. [CrossRef]

50. Reeuwijk, K.G.; Robroek, S.J.W.; Niessen, M.A.J.; Kraaijenhagen, R.A.; Vergouwe, Y.; Burdorf, A. The Prognostic Value of the Work Ability Index for Sickness Absence among Office Workers. PLoS ONE 2015, 10, e0126969. [CrossRef]

51. Costa, G.; Sartori, S. Ageing, working hours and work ability. Ergonomics 2007, 50, 1914-1930. [CrossRef]

52. Ilmarinen, J. Aging workers. Occup. Environ. Med. 2001, 58, 546. [CrossRef] [PubMed]

53. Rotenberg, L.; Portela, L.F.; Banks, B.; Griep, R.H.; Fischer, F.M.; Landsbergisd, P. A gender approach to work ability and its relationship to professional and domestic work hours among nursing personnel. Appl. Ergon. 2008, 39, 646-652. [CrossRef] [PubMed]

54. Müller, A.; Weigl, M.; Heiden, B.; Herbig, B.; Glaser, J.; Angerer, P. Selection, optimization and compensation in nursing: Exploration of job-specific strategies, scale development and age-specific association to work ability. J. Adv. Nurs. 2013, 69, 1630-1642. [CrossRef] [PubMed]

55. Demerouti, E.; Bakker, A.B.; Leiter, M. Burnout and job performance: The moderating role of selection, optimization, and compensation strategies. J. Occup. Health Psychol. 2014, 19, 96-107. [CrossRef] [PubMed]

56. Hedge, J.W.; Borman, W.C. The Oxford Handbook of Work and Aging; Oxford University Press: Oxford, UK, 2012.

57. Zacher, H.; Frese, M. Maintaining a focus on opportunities at work: The interplay between age, job complexity and the use of selection, optimization and compensation strategies. J. Organ. Behav. 2011, 32, 291-318. [CrossRef]

58. Müller, A.; Heiden, B.; Herbig, B.; Poppe, F.; Angerer, P. Improving well-being at work: A randomized controlled intervention based on selection, optimization, and compensation. J. Occup. Health Psychol. 2015, 21, 169-181. [CrossRef]

59. Schmitt, A.; Zacher, H.; Frese, M. The buffering effect of selection, optimization, and compensation strategy use on the relationship between problem-solving demands and occupational well-being: A daily diary study. Occup. Health Psychol. 2012, 17, 139-149. [CrossRef]

60. Müller, A.; Angerer, P.; Becker, A.; Gantner, M.; Gündel, H.; Heiden, B.; Herbig, B.; Herbst, K.; Poppe, F.; Schmook, R.; et al. Bringing Successful Aging Theories to Occupational Practice: Is Selective Optimization With Compensation Trainable? Work Aging Retire. 2018, 4, 161-174. [CrossRef]

61. Dang, C.D.; Li, F.; Yang, C. Measuring Firm Size in Empirical Corporate Finance. J. Bank. Financ. Jan. 2018, 86, 159-176. [CrossRef]

62. Li, F. Endogeneity in CEO power: A survey and experiment. Invest. Anal. J. 2016, 45, 149-162. [CrossRef]

(C) 2019 by the authors. Licensee MDPI, Basel, Switzerland. This article is an open access article distributed under the terms and conditions of the Creative Commons Attribution (CC BY) license (http:/ / creativecommons.org/licenses/by/4.0/). 